\title{
Molecular Chaperones as Prognostic Markers of Neuroblastoma
}

\author{
Yung-Feng Liao et al. ${ }^{*}$ \\ Institute of Cellular and Organismic Biology, Academia Sinica \\ Taipei, \\ Taiwan
}

\section{Introduction}

Neuroblastoma (NB) is a childhood tumor derived from sympathoadreanal lineage of the neural crest progenitor cells, and is the most common malignant disease of infancy, accounting for $96 \%$ of cases occurred before the age of 10 (Gurney et al., 1995, Maris and Matthay, 1999). The neuroblastoma cells exhibit characteristics of undifferentiated cells and often metastasize to distant organs (Maris and Matthay, 1999, Maris et al., 2007). Approximately, $60 \%$ of patients diagnosed with NB display a stage IV disease and a very poor prognosis. The 5-year survival rate of NB patients is no more than $30 \%$, even with aggressive therapy (Nishihira et al., 2000). As a result, $50 \%$ of the NB patients die from this disease that continues to be one of the most difficult challenges among pediatric tumors.

NB is quite a heterogeneous tumor and presents a broad clinical and biologic spectrum ranging from highly undifferentiated tumors with very poor outcomes to the most differentiated benign ganglioneuroma or NBs with high probability of spontaneous regression and hence favorable prognosis. The clinical presentation of NB can be categorized into three distinct patterns based on the tumor histology: (i) life-threatening progression; (ii) maturation to ganglioneuroblastoma (GNB) or ganglioneuroma (GN); and (iii) spontaneous regression (Pritchard and Hickman, 1994). Taking other biological variables into account, NBs can be categorized into two groups in terms of prognosis (Brodeur, 2003, Woods et al., 1992). One, the favorable NB, is associated with young age and

\footnotetext{
*Wen-Ming Hsu1, Hsinyu Lee ${ }^{3,4}$, Ming-Kuan $\mathrm{Hu}^{9}$, Hsueh-Fen Juan 3,5, Min-Chuan Huang8, Hsiu-Hao Chang2, Bo-Jeng Wang,,6, Yu-Yin Shih',6 and Yeou-Guang Tsay ${ }^{4}$

Departments of ${ }^{1}$ Surgery and ${ }^{2}$ Pediatrics, National Taiwan University Hospital and National Taiwan University College of Medicine;

${ }^{3}$ Department of Life Science and Institutes of 4 Zoology and ${ }^{5}$ Molecular and Cellular Biology, National Taiwan University;

${ }^{6}$ Institute of Cellular and Organismic Biology, Academia Sinica; ${ }^{7}$ Institute of Biochemistry and Molecular Biology and Proteomics Research Center, National Yang-Ming University;

${ }^{8}$ Graduate Institute of Anatomy and Cell Biology, National Taiwan University College of Medicine;

${ }^{9}$ School of Pharmacy, National Defense Medical Center;

Taipei

Taiwan
} 
early stage at diagnosis, triploid karyotypes with whole chromosome gains, and excellent clinical outcome despite minimal or no therapy. The other, the unfavorable NB, is associated with older age and advanced stage, and pseudodiploid karyotypes with structural changes including deletion of $1 \mathrm{p}$ or $11 \mathrm{q}$, unbalanced gain of $17 \mathrm{q}$ and/or amplification of the MYCN proto-oncogene. Patients with unfavorable NBs usually have a very poor outcome despite multimodality therapies including bone marrow transplantation. Furthermore, we have also previously shown that the biologic characteristics of NB tumors would significantly influence the surgical decision (Hsu et al., 2006). The role of gross total resection of the primary tumor, a high-risk operation, has been controversial in the treatment of NB, especially in advanced NB. We demonstrated that gross total resection of the primary tumor could carry favorable outcome only in a specific group of NB with certain biomarkers (Hsu et al., 2006). These lines of evidence suggest that a more detailed understanding of the clinical and biologic characteristics of NB is imperative for the selection of appropriate therapeutic intervention on these tumors in order to achieve effective treatment without unnecessary complications. In this review, we will briefly overview the molecular mechanisms implicated in the tumorigenesis of NB and discuss the pathological roles of three chaperone proteins in this tumor. A model will then be proposed to illustrate the aberrant functions of chaperone proteins in predisposing neuroblastic cells into the initiation of NB.

\section{The tumorigenesis of neuroblastoma}

Aberrant embryonic development of sympathetic nervous system has been suggested to underlie the tumorigenesis of NB. The molecular characterization of clinically relevant prognostic markers is likely to shed light on the molecular mechanisms governing the neuroblast development and lead to the identification of novel therapeutic targets of NB. Since NB exhibits great tendency to differentiate, intensive induction therapy of NB has been widely attempted to improve outcomes. Recent evidence suggests that NB cells exhibit capacity of differentiating into mature cells and can be forced to differentiate upon the treatment of retinoic acid, butyric acid, or cisplatin (Ijiri et al., 2000, Tonini, 1993). A number of molecules normally expressed during embryonic development, including HNK-1, neuropeptide $Y$, tyrosine hydroxylase, TrkA and CD44, are found in NB (Hoehner et al., 1996, Israel, 1993), suggesting that the tumorigenesis of NB could be a divergence of the embryonic development of the sympathetic nervous system. On the other hand, NB cells with better prognosis are often found to express markers indicative of cell differentiation, such as HNK-1 and TrkA (Cooper et al., 1992, Nakagawara et al., 1993). It is thus plausible that the tumorigenesis of NB might result from the defect in the differentiation of embryonic NB cells (Tonini, 1993). Interestingly, NB can regress spontaneously by apoptosis (Ijiri et al., 2000, Pritchard and Hickman, 1994). The expression of pro-apoptotic genes is evident in NB,that correlates with favorable prognosis, and the survival rate of NB patients is proportional to the expression levels of these genes (Hoehner et al., 1997). Inducers of differentiation, including retinoid acid and cisplatin, could promote apoptosis in NB cells (Tonini, 1993), and NB cells expressing TrkA may undergo cell death when deprived of nerve growth factor (NGF) (Nakagawara et al., 1993), suggesting that the deficient apoptosis of embryonic NB cells could lead to the tumorigenesis of NB. However, what factors may 
contribute to the regulation of NB cell differentiation or apoptosis is still unclear. Accumulated evidence has suggested that apoptosis and differentiation of NB cells might occur simultaneously (Ijiri et al., 2000, Tonini, 1993). Consistently, NB cells expressing TrkA can be induced to differentiate in the presence of NGF, while undergo apoptosis upon withdrawal of NGF (Nakagawara et al., 1993). It is thus conceivable that factors mediating the tumorigenesis of NB would affect the differentiation and apoptosis of the NB cells simultaneously.

NB tumors are highly vascular and autonomously produce a variety of angiogenic factors, such as VEGF, bFGF, Ang-2, TGF- $\beta$, and PDGF-A, that are commonly found in advancedstage tumors (Eggert et al., 2000). Although it is still debatable (Canete et al., 2000), the vascular index, as expressed by numbers of vessels per square millimeter of tissue area, has been shown to correlate with the adverse prognosis of NB patients (Meitar et al., 1996). Furthermore, the obstruction of angiogenesis may induce differentiation and apoptosis in NB (Wassberg et al., 1999), suggesting that the angiogenic factors produced by NB could also play an important role in the differentiation and apoptosis of NB cells.

Together, these data suggest that failure of either differentiation or regression by apoptotic death of NB cells is critical for the development of NB. This notion can be further supported by these findings (i) that the high frequency of spontaneous differentiation and regression can be observed in $4 \mathrm{~S}$ tumors as well as those detected by mass screening; (ii) that the neuroblastic tumors (NTs) in adrenal glands obtained from non-afflicted infants at autopsy indicates a high incidence of unrecognized spontaneous resolution; (iii) that expression of apoptosis-related genes has been demonstrated in NB; and (iv) that NB patients with higher apoptotic index have better prognosis. Along these lines, we will describe the functions of three chaperone proteins that are implicated in the differentiation of NB. The alteration of their functions, either individually or combinarotially, could result in the propensity for the neuroblastic cells to transform and initiate the tumorigenesis of NB.

Here, we summarize the roles of three newly identified favorable prognostic markers, whose functionality as chaperones are well-established, in the pathogenesis of NB. Although these biomarkers, including calreticulin, glucose-regulated protein 78, and glucoseregulated protein 75 , could be localized to different intracellular organelles, our recent studies have provided compelling evidence demonstrating that these biomarkers share an emerging function in actively governing the neuronal differentiation of neuroblastic cells. These new findings thus propose a model in which some chaperone proteins might not simply be a protein guardian in securing the normal folding of cellular proteins but could vigorously engage in crucial cellular functions by themselves.

\section{Molecular chaperones of tumorigenesis}

The enhanced expression of molecular chaperones have been found in a variety of tumors, and is often associated with an unfavorable prognosis and resistance to therapy (Calderwood et al., 2006). These molecular chaperones at high levels can promote tumorigenesis through facilitating the accumulation of overexpressed and mutated oncogenes and inhibiting apoptosis of tumor cells. According to Hanahan and Weinbeg (Hanahan and Weinberg, 2000), the tumorigenesis can be organized into six phenotypic changes in cellular functions: (i) autonomy in growth signaling; (ii) resistance to growth inhibition; (iii) evasion of apoptosis; (iv) unlimited proliferative potential; (v) persistent angiogenesis; and (vi) tissue invasion and 
metastasis. The increased expression of molecular chaperones thus could not only allow tumor cells acquire malignant capabilities, but also actively play a role in most stages of tumor development and the acquisition of drug resistance.

\subsection{Calreticulin}

Calreticulin (CRT) is a molecular chaperone primarily localized to endoplasmic reticulum, and has emerged as an early stage marker of NB. Although CRT is best known for its critical role in securing the correct folding and maturation of nascent proteins (Ellgaard and Helenius, 2003), it also involves in the regulation of $\mathrm{Ca}^{2+}$ homeostasis, the modulation of integrin-dependent adhesion, the alteration of $\mathrm{Ca}^{2+}$-elicited signaling, and the inhibition of the transcriptional activities of steroid receptors (Coppolino et al., 1997, Dedhar et al., 1994, Michalak et al., 1999). The expression of CRT can be up-regulated under stress conditions and apoptosis, suggesting CRT as a stress protein (Nakamura et al., 2000). Consistent with these findings, mice deficient of CRT exhibit significant brain defects (Rauch et al., 2000), suggesting an essential role of CRT in the embryonic development of nervous system.

The role of CRT in tumorigenesis has just begun to be elucidated, evidenced by the differential expression and localization of CRT in malignant versus non-malignant tissues. The nuclear localization of CRT in hepatocellular carcinoma and various carcinomas, but not in nonmalignant liver tissue, suggests that the interaction of calreticulin and nuclear matrix could be critical for the uncontrolled proliferation of carcinomas (Yoon et al., 2000). Furthermore, up-regulated expression of CRT can be observed in breast cancers, suggesting that CRT is pivotal for the malignant progression of carcinomas (Bini et al., 1997, Franzen et al., 1997). Interestingly, vasostatin, the N-terminal fragment of CRT, and the full-length CRT have been shown to suppress tumor growth by directly targeting endothelial cells to inhibit angiogenesis (Pike et al., 1998, Pike et al., 1999). A recent report further demonstrates that CRT can serve as a recognition ligand for LDL receptor-related protein (LRP) and signal for the removal of apoptotic cells in a CRT/LRP-dependent manner (Gardai et al., 2005). These findings depict dual functions of intracellular CRT and extracellular CRT in tumorigenesis. The former is likely to promote tumor growth by entering nuclei to alter the function of transcriptional machinery, while the latter could target specific surface receptors to hinder the growth of malignant cells.

The essential role of CRT in the differentiation of NB cells has recently been established. The up-regulated expression of CRT in NB cells, coincident with the alteration of integrin profile on the surface, is particularly prominent upon differentiation (Combaret et al., 1994, Gladson et al., 1997, Rozzo et al., 1993, Coppolino et al., 1997), substantiating an essential function of CRT in mediating integrin-dependent calcium signaling. CRT in differentiating NB cells is localized to plasma membrane and could play an essential role in neurite outgrowth (Xiao et al., 1999a, Xiao et al., 1999b). These results suggest that CRT in NB, unlike in other carcinomas, can be re-distributed to cell surface to antagonize tumor growth upon induced differentiation. To verify this hypothesis, we evaluate the association of clinicopathologic factors and patient survival with the expression of CRT in patients with NB to determine whether CRT could affect the tumor behavior of NB (Hsu et al., 2005a). Our data show that positive CRT expression is strongly correlated with differentiated histologies in sixty-eight NBs. Its expression is also closely associated with known favorable prognostic factors such as detected from mass screening, younger age 
( $\leq 1$ year) at diagnosis and early clinical stages, but is inversely correlated with MYCN amplification. Overall, NB patients with higher levels of CRT fare significantly better in long-term survival, substantiating CRT as an independent prognostic factor. Moreover, CRT expression also predicted better survival in patients with advanced-stage NB, and its absence predicted poor survival in patients whose tumor had no MYCN amplification. Altogether, CRT could actively play a part in the differentiation, apoptosis and angiogenesis of NB as well as the pathogenesis of NB.

\subsection{Glucose-regulated protein $\mathbf{7 8}$}

Glucose-regulated protein 78 (GRP78) is a member of the family of heat shock protein 70 (HSP70) that is localized at the endoplasmic reticulum (ER) (Gething, 1999). Like other ERresident chaperones, GRP78 is essential for the correct folding and translocation of newlysynthesized secretory proteins across the ER membrane, and is also required for the retrotranslocation of aberrant and misfolded polypeptides destined for degradation in proteasome (Gething, 1999). In addition to being a constituent of the quality control system in ER, GRP78 also contributes to the maintenance of $\mathrm{Ca}^{2+}$ homeostasis (Chevet et al., 1999). GRP78 expression in normal adult organs is generally maintained at low levels and could become escalated in tumors (Dong et al., 2004), suggesting that GRP78 is required for the propagation of cancers. Consistent with this finding, tumor progression in GRP78 heterozygous mice is significantly attenuated, accompanied by a longer latency period, reduced tumor size, and increased tumor apoptosis (Lee, 2007). Accumulated evidence also suggest that GRP78 overexpression could renders various cancers resistance to chemotherapy (Li and Lee, 2006). These findings provide the rationales for targeting GRP78 as an anticancer approach that could be used in conjunction with standard therapeutic agents to improve the prognosis.

Like other HSP70 family members, GRP78 is constitutively expressed at high levels in neuroepithelial cells of the neural tube, suggesting that GRP78 and other HSP70 proteins could play significant roles in the development and differentiation of neural tissue (Barnes and Smoak, 2000, Walsh et al., 1997). By using a rat pheochromocytoma cell line PC12 as a cellular model of neuroblastoma, the levels of GRP78 protein are significantly enhanced in PC12 cells that are induced by nerve growth factor (NGF) to differentiate (Satoh et al., 2000). The overexpression of exogenous GRP78 can further augment the neurite outgrowth induced by NGF, while the down-regulation of GRP78 blocks the NGF-induced neurite outgrowth (Satoh et al., 2000), suggesting a functional synergism between NGF signaling and GRP78 function with respect to neuronal differentiation. Consistently, the inhibition of cell death in NGF-deprived neuronal cells reduces of the levels of GRP78 transcripts, suggesting a functional role of GRP78 in neuronal cell death (Aoki et al., 1997). The possibility thus exists that GRP78 could affect the differentiation and apoptosis of NB and may have a role in the tumor behavior of this cancer. In supporting this view, data from our lab have confirmed the clinical importance of GRP78 in NB. In a cohort of 68 neuroblastic tumors, forty (58.8\%) of them display positive GRP78 expression by immunohistochemistry, and the positive GRP78 immunostaining is tightly correlated with differentiation histology of tumor and early clinical stages, but inversely correlated with MYCN amplification (Hsu et al., 2005b). Our findings also suggest that GRP78 expression could be an independent prognostic biomarker for favorable outcome in NB patients. Given that the differential roles 
of GRP78 in NB and other solid tumors, it would become increasingly critical to assess GRP78 expression level for the proper management of patients with NB versus other types of cancers.

\subsection{Glucose-regulated protein $\mathbf{7 5}$}

Glucose-regulated protein 75 (GRP75) is a member of heat shock protein 70 family and is first cloned from the cytoplasmic fraction of normal mouse fibroblast (Wadhwa et al., 1993). GRP75, also known as mortalin-2, is a member of mitochondrial molecular chaperones, but could also resides in other organelles, such as ER, plasma membrane, cytoplasmic vesicles, and cytosol (Kaul et al., 2002). GRP75 carries multiple cellular functions ranging from stress response, intracellular trafficking, antigen processing, control of cell proliferation, differentiation, and tumorigenesis (Wadhwa et al., 2002b). It has been shown that GRP75 is distributed in a pancytoplasmic pattern in normal cells but could be redistributed into a perinuclear mode in transformed cells (Wadhwa et al., 1995). The versatilities of GRP75's functions can also be exemplified by its interactions with many cellular proteins, including metabolic enzymes (e.g. diphosphomevalonate decarboxylase), mitochondrial proteins (e.g. voltage-dependent anion channel 1), and proteins involved in proliferation and differentiation (e.g. FGF-1, MKK7, and p53) (Wadhwa et al., 2003, Schwarzer et al., 2002, Wadhwa et al., 1998).

The tumorigenic role of GRP75 is shown by its colocalization with p53 in the perinuclear region of various cancers, possibly through taking part in the suppression of p53 expression (Wadhwa et al., 2002a, Wadhwa et al., 1998). GRP75 can thus serve as a functional chelator of p53 by sequestering it in cytoplasm to suppress p53-dependent gene expression. Consistent with these data, overexpression of GRP75 is found to be crucial for the changes from immortal to malignant phenotypes, leading to aggressive proliferative potential (Czarnecka et al., 2006). The expression of GRP75 is evidently up-regulated in a large number of tumorigenic human cell lines, implicating its overexpression as a marker of cell transformation (Wadhwa et al., 2006). In the acute myeloid leukemia HL-60 cells, the level of GRP75 is down-regulated upon differentiation, while overexpression of GRP75 is able to attenuate RA-induced differentiation and prevent apoptosis (Xu et al., 1999). Furthermore, GRP75 has been shown to be critical for the malignancy of breast cancer cells, and cells with higher levels of GRP75 are prone to exhibit an anchorage-independent phenotype and form tumors in nude mice (Wadhwa et al., 2006). Together, GRP75 actively involves in the molecular mechanisms governing the carcinogenesis of various tumors and could represent an ideal candidate for gene therapy.

The exact role of GRP75 in the tumorigenesis of neuroblastoma is still unclear. We have employed two-dimensional differential gel electrophoresis (2-D DIGE) to identify GRP75 as one of the most dramatically up-regulated proteins in differentiated NB cells. Immunohistochemical analyses of NB tissues further reveal that positive GRP75 immunostaining is strongly correlated with differentiated histologies, mass-screened tumors and early clinical stages, but inversely correlated with MYCN amplification. Consistent with these data, univariate and multivariate survival analyses demonstrate that GRP75 expression is an independent favorable prognostic factor. Our data substantiate an essential role of GRP75 in the differentiation of neuroblastoma and establish a novel function of GRP75 in promoting the differentiation of NB cells. Whether GRP75 localized at different 
intracellular compartments can play distinctive cellular functions is not clear. Nevertheless, our data demonstrate for the first time that the change in the intracellular distribution of GRP75 coincides with the development of neuronal phenotypes of differentiated NB cells, strongly suggesting a functional role of GRP75 in neuronal differentiation.

\section{Conclusion}

Current data have clearly suggested that the tumorigenesis of NB is controlled by a complex mechanism and is distinct from that of other cancers. This process could be driven by the intricate interactions among many gene products in multiple pathways. The best-known examples of molecular chaperones involved in the regulation of neuronal differentiation, such as CRT, GRP78, and GRP75, also turn out to be favorable prognostic markers of NB, paving the way for us to unveil the functional roles of molecular chaperones in the tumorigenesis of NB. A recent study has shown that GRP75 and GRP78, another favorable prognostic marker of NB (Hsu et al., 2005b), could bind to RHAMM with an associated downregulation of RHAMM in Jurkat cells (Kuwabara et al., 2006). The GRP75/78-RHAMM complex could then bind to the microtubules to stabilize the microtubules in the interphase and prevent the depolymerization of microtubules for the progression of mitosis (Kuwabara et al., 2006). The essential role of RHAMM in neurite extension has been suggested (Nagy et al., 1995), and the expression of RHAMM has been linked to the progression and metastasis of a variety of cancers (Maxwell et al., 2005). The possibility thus exists that the pancytoplasmic GRP75 in differentiating NB cells, along with GRP78, may prevent these cells from engaging into mitosis by binding with and downregulating RHAMM while promoting the neurite formation simultaneously. These findings thus suggest that the nonchepraone effects of these molecular chaperones might play an even bigger role in tumorigenesis of $\mathrm{NB}$ and other cancers.

A number of molecular chaperones of ER and mitochondria, such as CRT, GRP78, GRP75, and GRP94, whose expression is affected by tumorigenic pathways could be re-distributed outside their primary resident organelles, such as plasma membrane, neurites, and nuclei, upon differentiation. Data from others and our own labs have clearly demonstrated the "offsite" localization of these molecular chaperones. There may also be other mechanisms for the re-localization of chaperones to the nuclei and neurites that are associated with the cellular transformation. In contrast, molecular chaperones, such as calnexin in ER, that are constitutively expressed despite oncogenic transformation would mostly remain immotile during differentiation of NB. It remains to be determined whether the off-site expression of molecular chaperones is restricted to specific types of cancer and what fractions of these chaperones are presented on different cellular locations in tumor cells. Nonetheless, in certain cancers, the surface-localized GRP78 has been utilized as a beacon to deliver therapeutic agents specifically into cancer cells (Fu and Lee, 2006). Biologic factors that predict a favorable outcome for neuroblastoma patients are usually associated with differentiation or regression of neuroblastoma cells and early clinical stages. It remains to be investigated whether the expression of these differentiation-associated molecular chaperones, including HSP45, GRP78, GRP75, and calreticulin, in neuroblastic tumors would be sufficient to counteract the MYCN-elicited tumorigenesis of NB. In summary, molecular chaperones that are expressed in increased amounts in NB during differentiation 
could play an essential role in NB by slowing down its autonomous growth through promoting neuronal differentiation. The increased abundance of molecular chaperones in differentiated NB cells also offers tempting targets for the development of gene therapy that can attenuate the malignant phenotype of NB.

\section{Acknowledgements}

This work was supported by the National Science Council, Taiwan and Academia Sinica.

\section{References}

Aoki, T., Koike, T., Nakano, T., Shibahara, K., Kondo, S., Kikuchi, H. \& Honjo, T. (1997) Induction of Bip mRNA upon programmed cell death of differentiated PC12 cells as well as rat sympathetic neurons. J Biochem (Tokyo), 121, 122-7.

Barnes, J. A. \& Smoak, I. W. (2000) Glucose-regulated protein 78 (GRP78) is elevated in embryonic mouse heart and induced following hypoglycemic stress. Anat Embryol (Berl), 202, 67-74.

Bini, L., Magi, B., Marzocchi, B., Arcuri, F., Tripodi, S., Cintorino, M., Sanchez, J. C., Frutiger, S., Hughes, G., Pallini, V., Hochstrasser, D. F. \& Tosi, P. (1997) Protein expression profiles in human breast ductal carcinoma and histologically normal tissue. Electrophoresis, 18, 2832-41.

Brodeur, G. M. (2003) Neuroblastoma: biological insights into a clinical enigma. Nat Rev Cancer, 3, 203-16.

Calderwood, S. K., Khaleque, M. A., Sawyer, D. B. \& Ciocca, D. R. (2006) Heat shock proteins in cancer: chaperones of tumorigenesis. Trends Biochem Sci, 31, 164-72.

Canete, A., Navarro, S., Bermudez, J., Pellin, A., Castel, V. \& Llombart-Bosch, A. (2000) Angiogenesis in neuroblastoma: relationship to survival and other prognostic factors in a cohort of neuroblastoma patients. J Clin Oncol, 18, 27-34.

Chevet, E., Jakob, C. A., Thomas, D. Y. \& Bergeron, J. J. (1999) Calnexin family members as modulators of genetic diseases. Semin Cell Dev Biol, 10, 473-80.

Combaret, V., Coll, J. L. \& Favrot, M. C. (1994) Expression of integrin and CD44 adhesion molecules on neuroblastoma: the relation to tumor aggressiveness and embryonic neural-crest differentiation. Invasion Metastasis, 14, 156-63.

Cooper, M. J., Steinberg, S. M., Chatten, J., Evans, A. E. \& Israel, M. A. (1992) Plasticity of neuroblastoma tumor cells to differentiate along a fetal adrenal ganglionic lineage predicts for improved patient survival. J Clin Invest, 90, 2402-8.

Coppolino, M. G., Woodside, M. J., Demaurex, N., Grinstein, S., ST-Arnaud, R. \& Dedhar, S. (1997) Calreticulin is essential for integrin-mediated calcium signalling and cell adhesion. Nature, 386, 843-7.

Czarnecka, A. M., Campanella, C., Zummo, G. \& Cappello, F. (2006) Mitochondrial chaperones in cancer: from molecular biology to clinical diagnostics. Cancer Biol Ther, 5, 714-20.

Dedhar, S., Rennie, P. S., Shago, M., Hagesteijn, C. Y., Yang, H., Filmus, J., Hawley, R. G., Bruchovsky, N., Cheng, H., Matusik, R. J. \& et al. (1994) Inhibition of nuclear hormone receptor activity by calreticulin. Nature, 367, 480-3.

Dong, D., Dubeau, L., Bading, J., Nguyen, K., Luna, M., Yu, H., Gazit-Bornstein, G., Gordon, E. M., Gomer, C., Hall, F. L., Gambhir, S. S. \& Lee, A. S. (2004) Spontaneous and 
controllable activation of suicide gene expression driven by the stress-inducible grp78 promoter resulting in eradication of sizable human tumors. Hum Gene Ther, $15,553-61$.

Eggert, A., Ikegaki, N., Kwiatkowski, J., Zhao, H., Brodeur, G. M. \& Himelstein, B. P. (2000) High-level expression of angiogenic factors is associated with advanced tumor stage in human neuroblastomas. Clin Cancer Res, 6, 1900-8.

Ellgaard, L. \& Helenius, A. (2003) Quality control in the endoplasmic reticulum. Nat Rev Mol Cell Biol, 4, 181-91.

Franzen, B., Linder, S., Alaiya, A. A., Eriksson, E., Fujioka, K., Bergman, A. C., Jornvall, H. \& Auer, G. (1997) Analysis of polypeptide expression in benign and malignant human breast lesions. Electrophoresis, 18, 582-7.

Fu, Y. \& Lee, A. S. (2006) Glucose regulated proteins in cancer progression, drug resistance and immunotherapy. Cancer Biol Ther, 5, 741-4.

Gardai, S. J., Mcphillips, K. A., Frasch, S. C., Janssen, W. J., Starefeldt, A., Murphy-Ullrich, J. E., Bratton, D. L., Oldenborg, P. A., Michalak, M. \& Henson, P. M. (2005) CellSurface Calreticulin Initiates Clearance of Viable or Apoptotic Cells through transActivation of LRP on the Phagocyte. Cell, 123, 321-334.

Gething, M. J. (1999) Role and regulation of the ER chaperone BiP. Semin Cell Dev Biol, 10, 465-72.

Gladson, C. L., Dennis, C., Rotolo, T. C., Kelly, D. R. \& Grammer, J. R. (1997) Vitronectin expression in differentiating neuroblastic tumors: integrin alpha $\mathrm{v}$ beta 5 mediates vitronectin-dependent adhesion of retinoic-acid-differentiated neuroblastoma cells. Am J Pathol, 150, 1631-46.

Gurney, J. G., Severson, R. K., Davis, S. \& Robison, L. L. (1995) Incidence of cancer in children in the United States. Sex-, race-, and 1-year age-specific rates by histologic type. Cancer, 75, 2186-95.

Hanahan, D. \& Weinberg, R. A. (2000) The hallmarks of cancer. Cell, 100, 57-70.

Hoehner, J. C., Gestblom, C., Hedborg, F., Sandstedt, B., Olsen, L. \& Pahlman, S. (1996) A developmental model of neuroblastoma: differentiating stroma-poor tumors' progress along an extra-adrenal chromaffin lineage. Lab Invest, 75, 659-75.

Hoehner, J. C., Gestblom, C., Olsen, L. \& Pahlman, S. (1997) Spatial association of apoptosisrelated gene expression and cellular death in clinical neuroblastoma. Br J Cancer, 75 , 1185-94.

Hsu, W. M., Hsieh, F. J., Jeng, Y. M., Kuo, M. L., Chen, C. N., Lai, D. M., Hsieh, L. J., Wang, B. T., Tsao, P. N., Lee, H., Lin, M. T., Lai, H. S. \& Chen, W. J. (2005a) Calreticulin expression in neuroblastoma--a novel independent prognostic factor. Ann Oncol, $16,314-21$.

Hsu, W. M., Hsieh, F. J., Jeng, Y. M., Kuo, M. L., Tsao, P. N., Lee, H., Lin, M. T., Lai, H. S., Chen, C. N., Lai, D. M. \& Chen, W. J. (2005b) GRP78 expression correlates with histologic differentiation and favorable prognosis in neuroblastic tumors. Int $J$ Cancer, 113, 920-7.

Hsu, W. M., Jen, Y. M., Lee, H., Kuo, M. L., Tsao, P. N., Chen, C. N., Lai, D. M., Lin, M. T., Lai, H. S., Chen, W. J. \& Hsieh, F. J. (2006) The influence of biologic factors on the surgical decision in advanced neuroblastoma. Ann Surg Oncol, 13, 238-44.

Ijiri, R., Tanaka, Y., Kato, K., Misugi, K., Nishihira, H., Toyoda, Y., Kigasawa, H., Nishi, T., Takeuchi, M., Aida, N. \& Momoi, T. (2000) Clinicopathologic study of mass- 
screened neuroblastoma with special emphasis on untreated observed cases: a possible histologic clue to tumor regression. Am J Surg Pathol, 24, 807-15.

Israel, M. A. (1993) Disordered differentiation as a target for novel approaches to the treatment of neuroblastoma. Cancer, 71, 3310-3.

Kaul, S. C., Taira, K., Pereira-Smith, O. M. \& Wadhwa, R. (2002) Mortalin: present and prospective. Exp Gerontol, 37, 1157-64.

Kuwabara, H., Yoneda, M., Hayasaki, H., Nakamura, T. \& Mori, H. (2006) Glucose regulated proteins 78 and 75 bind to the receptor for hyaluronan mediated motility in interphase microtubules. Biochem Biophys Res Commun, 339, 971-6.

Lee, A. S. (2007) GRP78 induction in cancer: therapeutic and prognostic implications. Cancer Res, 67, 3496-9.

Li, J. \& Lee, A. S. (2006) Stress induction of GRP78/BiP and its role in cancer. Curr Mol Med, $6,45-54$.

Maris, J. M., Hogarty, M. D., Bagatell, R. \& Cohn, S. L. (2007) Neuroblastoma. Lancet, 369, 2106-20.

Maris, J. M. \& Matthay, K. K. (1999) Molecular biology of neuroblastoma. J Clin Oncol, 17, 2264-79.

Maxwell, C. A., Keats, J. J., Belch, A. R., Pilarski, L. M. \& Reiman, T. (2005) Receptor for hyaluronan-mediated motility correlates with centrosome abnormalities in multiple myeloma and maintains mitotic integrity. Cancer Res, 65, 850-60.

Meitar, D., Crawford, S. E., Rademaker, A. W. \& Cohn, S. L. (1996) Tumor angiogenesis correlates with metastatic disease, N-myc amplification, and poor outcome in human neuroblastoma. J Clin Oncol, 14, 405-14.

Michalak, M., Corbett, E. F., Mesaeli, N., Nakamura, K. \& Opas, M. (1999) Calreticulin: one protein, one gene, many functions. Biochem J, $344 \mathrm{Pt}$ 2, 281-92.

Nagy, J. I., Hacking, J., Frankenstein, U. N. \& Turley, E. A. (1995) Requirement of the hyaluronan receptor RHAMM in neurite extension and motility as demonstrated in primary neurons and neuronal cell lines. J Neurosci, 15, 241-52.

Nakagawara, A., Arima-Nakagawara, M., Scavarda, N. J., Azar, C. G., Cantor, A. B. \& Brodeur, G. M. (1993) Association between high levels of expression of the TRK gene and favorable outcome in human neuroblastoma. N Engl J Med, 328, 847-54.

Nakamura, K., Bossy-Wetzel, E., Burns, K., Fadel, M. P., Lozyk, M., Goping, I. S., Opas, M., Bleackley, R. C., Green, D. R. \& Michalak, M. (2000) Changes in endoplasmic reticulum luminal environment affect cell sensitivity to apoptosis. J Cell Biol, 150, 731-40.

Nishihira, H., Toyoda, Y., Tanaka, Y., Ijiri, R., Aida, N., Takeuchi, M., Ohnuma, K., Kigasawa, H., Kato, K. \& Nishi, T. (2000) Natural course of neuroblastoma detected by mass screening: s 5-year prospective study at a single institution. J Clin Oncol, 18, 3012-7.

Pike, S. E., Yao, L., Jones, K. D., Cherney, B., Appella, E., Sakaguchi, K., Nakhasi, H., TeruyaFeldstein, J., Wirth, P., Gupta, G. \& Tosato, G. (1998) Vasostatin, a calreticulin fragment, inhibits angiogenesis and suppresses tumor growth. J Exp Med, 188, 234956.

Pike, S. E., Yao, L., Setsuda, J., Jones, K. D., Cherney, B., Appella, E., Sakaguchi, K., Nakhasi, H., Atreya, C. D., Teruya-Feldstein, J., Wirth, P., Gupta, G. \& Tosato, G. (1999) 
Calreticulin and calreticulin fragments are endothelial cell inhibitors that suppress tumor growth. Blood, 94, 2461-8.

Pritchard, J. \& Hickman, J. A. (1994) Why does stage 4s neuroblastoma regress spontaneously? Lancet, 344, 869-70.

Rauch, F., Prud'homme, J., Arabian, A., Dedhar, S. \& ST-Arnaud, R. (2000) Heart, brain, and body wall defects in mice lacking calreticulin. Exp Cell Res, 256, 105-11.

Rozzo, C., Ratti, P., Ponzoni, M. \& Cornaglia-Ferraris, P. (1993) Modulation of alpha 1 beta 1, alpha 2 beta 1 and alpha 3 beta 1 integrin heterodimers during human neuroblastoma cell differentiation. FEBS Lett, 332, 263-7.

Satoh, T., Furuta, K., Tomokiyo, K., Nakatsuka, D., Tanikawa, M., Nakanishi, M., Miura, M., Tanaka, S., Koike, T., Hatanaka, H., Ikuta, K., Suzuki, M. \& Watanabe, Y. (2000) Facilitatory roles of novel compounds designed from cyclopentenone prostaglandins on neurite outgrowth-promoting activities of nerve growth factor. $J$ Neurochem, 75, 1092-102.

Schwarzer, C., Barnikol-Watanabe, S., Thinnes, F. P. \& Hilschmann, N. (2002) Voltagedependent anion-selective channel (VDAC) interacts with the dynein light chain Tctex1 and the heat-shock protein PBP74. Int J Biochem Cell Biol, 34, 1059-70.

Tonini, G. P. (1993) Neuroblastoma: the result of multistep transformation? Stem Cells, 11, 276-82.

Wadhwa, R., Kaul, S. C., Ikawa, Y. \& Sugimoto, Y. (1993) Identification of a novel member of mouse hsp70 family. Its association with cellular mortal phenotype. J Biol Chem, 268, 6615-21.

Wadhwa, R., Pereira-Smith, O. M., Reddel, R. R., Sugimoto, Y., Mitsui, Y. \& Kaul, S. C. (1995) Correlation between complementation group for immortality and the cellular distribution of mortalin. Exp Cell Res, 216, 101-6.

Wadhwa, R., Taira, K. \& Kaul, S. C. (2002a) An Hsp70 family chaperone, mortalin/mthsp70/PBP74/Grp75: what, when, and where? Cell Stress Chaperones, 7, 309-16.

Wadhwa, R., Taira, K. \& Kaul, S. C. (2002b) Mortalin: a potential candidate for biotechnology and biomedicine. Histol Histopathol, 17, 1173-7.

Wadhwa, R., Takano, S., Kaur, K., Deocaris, C. C., Pereira-Smith, O. M., Reddel, R. R. \& Kaul, S. C. (2006) Upregulation of mortalin/mthsp70/Grp75 contributes to human carcinogenesis. Int J Cancer, 118, 2973-80.

Wadhwa, R., Takano, S., Robert, M., Yoshida, A., Nomura, H., Reddel, R. R., Mitsui, Y. \& Kaul, S. C. (1998) Inactivation of tumor suppressor p53 by mot-2, a hsp70 family member. J Biol Chem, 273, 29586-91.

Wadhwa, R., Yaguchi, T., Hasan, M. K., Taira, K. \& Kaul, S. C. (2003) Mortalin-MPD (mevalonate pyrophosphate decarboxylase) interactions and their role in control of cellular proliferation. Biochem Biophys Res Commun, 302, 735-42.

Walsh, D., Li, Z., Wu, Y. \& Nagata, K. (1997) Heat shock and the role of the HSPs during neural plate induction in early mammalian CNS and brain development. Cell Mol Life Sci, 53, 198-211.

Wassberg, E., Hedborg, F., Skoldenberg, E., Stridsberg, M. \& Christofferson, R. (1999) Inhibition of angiogenesis induces chromaffin differentiation and apoptosis in neuroblastoma. Am J Pathol, 154, 395-403. 
Woods, W. G., Lemieux, B. \& Tuchman, M. (1992) Neuroblastoma represents distinct clinical-biologic entities: a review and perspective from the Quebec Neuroblastoma Screening Project. Pediatrics, 89, 114-8.

Xiao, G., Chung, T. F., Fine, R. E. \& Johnson, R. J. (1999a) Calreticulin is transported to the surface of NG108-15 cells where it forms surface patches and is partially degraded in an acidic compartment. J Neurosci Res, 58, 652-62.

Xiao, G., Chung, T. F., Pyun, H. Y., Fine, R. E. \& Johnson, R. J. (1999b) KDEL proteins are found on the surface of NG108-15 cells. Brain Res Mol Brain Res, 72, 121-8.

Xu, J., Xiao, H. H. \& Sartorelli, A. C. (1999) Attenuation of the induced differentiation of HL60 leukemia cells by mitochondrial chaperone HSP70. Oncol Res, 11, 429-35.

Yoon, G. S., Lee, H., Jung, Y., Yu, E., Moon, H. B., Song, K. \& Lee, I. (2000) Nuclear matrix of calreticulin in hepatocellular carcinoma. Cancer Res, 60, 1117-20. 


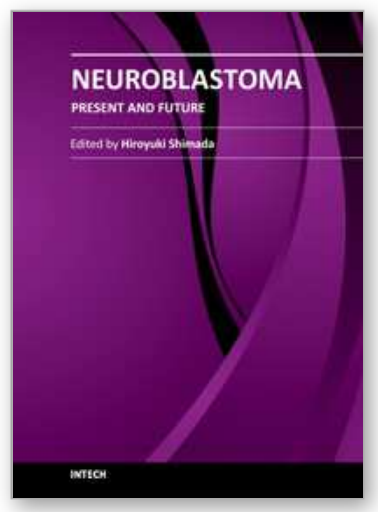

\author{
Neuroblastoma - Present and Future \\ Edited by Prof. Hiroyuki Shimada
}

ISBN 978-953-307-016-2

Hard cover, 366 pages

Publisher InTech

Published online 08, February, 2012

Published in print edition February, 2012

Neuroblastoma, once called "enigmatic", due to "unpredictable" clinical behaviors, is composed of biologically diverse tumors. Molecular/genomic properties unique to the individual tumors closely link to the clinical outcomes of patients. Establishing risk stratification models after analyzing biologic characteristics of each case has made a great success in patient management. However, the trend of improving survival rates in neuroblastoma over the last 30 years has started to level off, and currently available treatment modalities have almost reached to their maximized intensity. Furthermore, aggressive treatment causes significant long-term morbidities to the survivors. We really need to make the next step to the level of personalized medicine with more precise understanding of neuroblastoma biology. This book includes useful data and insights from the world's experts in this field. I believe this book can make an excellent contribution to all the investigators working hard and fighting for the children stricken by this disease.

\title{
How to reference
}

In order to correctly reference this scholarly work, feel free to copy and paste the following:

Yung-Feng Liao, Wen-Ming Hsu, Hsinyu Lee, Ming-Kuan Hu, Hsueh-Fen Juan, Min-Chuan Huang, Hsiu-Hao Chang, Bo-Jeng Wang, Yu-Yin Shih and Yeou-Guang Tsay (2012). Molecular Chaperones as Prognostic Markers of Neuroblastoma, Neuroblastoma - Present and Future, Prof. Hiroyuki Shimada (Ed.), ISBN: 978953-307-016-2, InTech, Available from: http://www.intechopen.com/books/neuroblastoma-present-andfuture/molecular-chaperones-as-prognostic-markers-of-neuroblastoma

\section{INTECH}

open science | open minds

\section{InTech Europe}

University Campus STeP Ri

Slavka Krautzeka 83/A

51000 Rijeka, Croatia

Phone: +385 (51) 770447

Fax: +385 (51) 686166

www.intechopen.com

\section{InTech China}

Unit 405, Office Block, Hotel Equatorial Shanghai

No.65, Yan An Road (West), Shanghai, 200040, China

中国上海市延安西路65号上海国际贵都大饭店办公楼405单元

Phone: +86-21-62489820

Fax: $+86-21-62489821$ 
(C) 2012 The Author(s). Licensee IntechOpen. This is an open access article distributed under the terms of the Creative Commons Attribution 3.0 License, which permits unrestricted use, distribution, and reproduction in any medium, provided the original work is properly cited. 